\title{
The genetic basis of facial skeletal characteristics and its relation with orthodontics
}

\author{
Derya Germec Cakan ${ }^{1}$ \\ Feyza Ulkur ${ }^{1}$ \\ Tulin (Uğur) Taner ${ }^{2}$
}

\begin{abstract}
Successful treatment of any orthodontic problem depends on an appropriate diagnosis of its etiology. It is well known that the genetics, as well as environmental factors, play an important role on the etiology of skeletal anomalies. Recent studies and advances in genetic sciences allowed the orthodontists to better understand the effects of genetics on the etiology of dentofacial characteristics and pathologies which in turn supported the effects of the genes in the development of dentofacial complex. In orthodontic practice, the genetic basis of a skeletal anomaly should also be considered during the diagnosis. Therefore orthodontic treatment plan should be chosen accordingly. However, further genetic studies are required to clearly determine all the specific genes leading to a particular skeletal variability caused by the polygenic nature of craniofacial traits. This article includes the current information on the association between orthodontics and genetics, an outline of the evidence based impact of heredity on dentofacial development as a review of the etiological factors of skeletal anomalies from the genetic point of view. (Eur J Dent 2012;6:340-345)
\end{abstract}

Key words: Genetics; orthodontics; facial skeletal anomalies

\section{INTRODUCTION}

The pioneering work of Gregor Mendel has initiated an interest in the field of genetics in the $19^{\text {th }}$ century and since then; genetics has been an important part of the studies carried in both biological and medical sciences. In orthodontics, the effects of genetics on the etiology of some dento-

1 Department of Orthodontics, Faculty of Dentistry, Yeditepe University, Istanbul, TURKIYE

2 Department of Orthodontics, Faculty of Dentistry, Hacettepe University, Ankara, TURKIYE

- Corresponding author: Dr. Derya Germec Cakan Department of Orthodontics, Faculty of Dentistry, Yeditepe University, Bagdat cad. No 238 Goztepe Istanbul, TURKIYE

Tel: +902163636044 / 6425

Fax: +902163636211

Email: dgermecAgmail.com facial characteristics and pathologies have come to light. Understanding the role of genetics is becoming necessary in diagnosis and treatment planning. Since the genetic proof is directly related to the diagnosis of familial dentofacial problems, modern orthodontists need to be aware of the basis of the genetic sciences, recent advances in the genetic researches and their application in the orthodontic practice. Once the hereditary factors are determined and isolated, the clinician may clearly ascertain and distinguish the environmental factors and carry out the treatment plan according to etiology. Therefore, it is a necessity to clearly outline the association between genetics and orthodontics. Although, there has been extensive literature concerning genetic basis of the dentofacial abnormalities and malocclusions, data 
provided by these studies were quite sparse. Furthermore, studies dealing with genetics constituted only the $0.5 \%$ of the total in the orthodontic journals since 1980's, ${ }^{1}$ the majority of which were published in non-orthodontic journals.

The objectives of this review were (1) to collect the comprehensive data about the interaction between orthodontics and genetics, (2) to add the current genetic information in the orthodontic literature, (3) to discuss the evidence based impact of heredity on the development of malocclusions and (4) to introduce the cause and the consequence relationships between genetics and malocclusions.

The effects of genetics in dentofacial skeletal characteristics

Malocclusion is a developmental problem. It is known that both hereditary and environmental factors have important influences on craniofacial development. However, one might not be able to determine for certain whether the malocclusions are determined by the genetic code or environmental factors or a combination of both. ${ }^{2}$ The relative importance of environment versus heredity has been controversial since the days of Angle. For the majority of the malocclusions, the etiology could not be easily categorized. However, rapid advances in molecular genetics have been providing new information about growth and development.

Evidence gained from population studies, especially family and twin studies, have shown that genetic factors play an important role in the etiology of malocclusions. ${ }^{3-5}$ On the other hand, research on siblings and even identical twins suggests a significant role for environmental factors besides genetic factors in the development of occlusion. ${ }^{4}$

Twin studies have provided a unique tool to evaluate the interactions between the hereditary structure and environmental factors as suggested by Galton for the first time. ${ }^{6}$ As twin studies are relatively easier, they are more frequently used in order to obtain heritability estimates. ${ }^{7}$ There has been extensive literature concerning monozygotic and dizygotic twin samples investigating the interaction between the heredity and the craniofacial complex. ${ }^{8-16}$ Significant hereditary variations in the anterior cranial base, mandibular body length, total facial height and lower facial height were shown in monozygotic adult twins. ${ }^{8}$ Hereditary factors were found to be responsible for only the $40 \%$ of the skeletal and dental variations resulting in a malocclusion and the genetic component was higher for skeletal pattern than for dental features. ${ }^{11}$ Similarly, the assessment of the longitudinal data of the siblings revealed that the heritability of skeletal characteristics was stronger than the heritability of dental characteristics. ${ }^{17} \mathrm{~A}$ series of studies by Corruccini et al9,12,13 also showed variable and frequently insignificant genetic variance for dental characteristics such as, sagittal molar relationship, overbite, overjet, posterior crossbite and rotations of anterior teeth. The study of genetic influence on dental arch form and size demonstrated the predominant effect of environmental factors rather than genetic ones. ${ }^{18}$ In another twin study, the evaluation of the dental arch and the structure of individual teeth of several monozygotic twin couples led to the conclusion that identical twins were not occlusally identical. ${ }^{10}$ The existence of a genetic component is likely to be present where facial proportions and jaw relationships influence the characteristics of a malocclusion. However, dental variations seem to be determined more frequently by the environment.

The role of heredity has been extensively investigated as one of the causes of malocclusion. In craniometrical and cephalometric studies of facial similarities, the evidence has supported the concept that facial form was mostly a product of the person's genotype ${ }^{19-23}$ and therefore facial appearance seems to have a familial tendency. The method of superimposing lateral cephalograms of siblings on those of their parents to evaluate the similarities of craniofacial bones and profiles, revealed a concordance for many craniofacial structures. ${ }^{44,25}$ In 1970, Hunter, using linear measurements on lateral cephalograms, demonstrated that there is a stronger genetic component of variability for measurements in vertical dimension, rather than for measurements in the sagittal dimension. ${ }^{25}$ Manfredi et al, ${ }^{16}$ in a more recent study on monozygotic twins, dizygotic twins and samesex siblings, assessed the inheritance traits of the orthodontic cephalometric parameters and they also suggested that the vertical parameters were more genetically controlled than the anteroposterior ones, heritability seemed to be expressed more anteriorly than posteriorly and mandibular shape seemed to be determined more genetically than the mandibular size. In accordance with 
these findings, Savoye et $\mathrm{al}^{26}$ also reported that the vertical proportions are highly under genetic control. The most frequent inherited malocclusion was found to be the facial deformity and openbite malocclusion with dolichofacial pattern. The higher prevalence of anterior openbite in black population compared to the white population and the higher prevalence of deepbite in whites may reflect a different inherent facial morphology rather than environmental factors. ${ }^{27}$

Although, the inheritance of the anteroposterior dimensions have been found to be lower than the vertical dimensions, certain malocclusions caused by sagittal discrepancies of the jaws show a familial tendency. The influence of genetics on facial features was obvious in some families. ${ }^{28}$ Especially, this was the case with the Class III malocclusions. This phenotype has been known for its appearance in certain European noble families such as Hapsburg royal family. ${ }^{28}$ According to pedigree analysis, the mandibular prognathism was found to be segregated during 23 generations in the thirteenth of those families and its penetrance was $95,5 \% .^{30}$ Different inheritance models have been suggested for this malocclusion, such as simple recessive ${ }^{31}$ or autosomal dominant with incomplete penetrance. ${ }^{32}$ In most of the cases, the mandibular prognathism have been accepted as a polygenic trait which means the phenotypic trait is caused by the simultaneous segregation of many genes. But in some cases, this phenotype has been thought to be determined by a single dominant gene. In a study of Litton et al, ${ }^{33}$ a group of probands, siblings and parents with Class III malocclusion was analyzed and in $1 / 3$ of the parents of the subjects severe mandibular prognathism was observed. They also followed the way of transmission and found out that if the number of females and males are equal, there was no association between genders. Suzuki (1962) ${ }^{34}$ studied on Japanese families and reported that in the index cases, in comparison to families of individuals with normal occlusion $(7.5 \%)$, there was a significantly higher incidence of mandibular prognatism in other members of their family (34.3\%). In their study results Schulze and Weise $(1965)^{35}$ also reported that concordance of mandibular prognatism on monozygotic twins was six times higher than dizygotic twins.

As in Class III problems, there is an inherited tendency toward retrognathic facial proportions and most of the Class II malocclusions are likely to be genetically controlled. ${ }^{27}$ In 1975, Harris $^{36}$ suggested the concept of polygenic inheritance for Class II division 1 malocclusions. The other malocclusion type in the "Class II" category is Class II division 2 malocclusion and is characterized by a well-developed mandibular basal bone, prominent chin, decreased lower facial height with anterior rotation of the mandible and smaller mesiodistal tooth size ${ }^{37}$ Although, the phenotypic traits of Class II division 2 malocclusion are obviously different than Class II division 1 malocclusion's traits, both malocclusions have polygenic inheritance in common. The results of the twin studies showed that the identical twins demonstrated $100 \%$ concordance for Class II division 2 malocclusion, indicating a strong genetic influence in the development of Class II division 2 deep-bite malocclusions. ${ }^{3}$ Later in 1998, the heritable skeletal and dental pattern of this malocclusion was supported by Peck and coworkers. ${ }^{37}$ In Marcovic (1992)'s clinical and cephalometric study intra and inter pair comparisons of 114 Class II division 2 malocclusions, 48 twin pairs and six sets of triplets were made. The concordance-disconcordance rates for monozygotic and dizygotic twins were determined. 100 per cent of the monozygotic twin pairs were concordant and almost 90 per cent of the dizygotic twin pairs showed disconcordance. ${ }^{5}$ As a result of these studies complete penetrance and variable expressivity of autosomal dominant genetic impression is indisputable. In addition to these studies in a polygenic model rather than being the effect of a single gene for entire occlusal malformation, a simultaneous expression of a number of genetically morphological traits are determined Furthermore, the presence of strong masticatory muscle pattern in Class II division 2 cases could have been explained by the genetically determined muscular and neuromuscular system. ${ }^{15}$

\section{Malocclusions associated with genetic syndromes}

In some cases, the malocclusions with severe skeletal discrepancies might be accompanied by a genetic syndrome. Some of the genetic syndromes are known to influence the development of craniofacial complex. Chromosomal aberrations, deficiencies, transpositions, breakage, deletions, 
or enlargements usually lead to abnormal development of the first branchial arch. ${ }^{38}$ This genetic situation results in micrognathia, malocclusions, facial asymmetry, facial and oral clefts, oligodontia and other dentofacial disorders accompanied by different types of deformities and deficiencies in other parts of the body. ${ }^{39}$ Mandibular deficiency associated genetic syndromes are Pierre-Robin, Treacher Collins and Marfan syndromes. PierreRobin sequence is an etiologically heterogeneous disorder ${ }^{40}$ and shows autosomal recessive inheritance. An X-linked form also exists. ${ }^{41}$

Treacher Collins syndrome is an autosomal dominant monogenic disorder caused by mutation in the treacle gene (TCOF1) mapped to the long arm of chromosome 5. It affects the craniofacial development and expresses itself as micrognathia, hypoplastic zygomatic bones and frequently cleft palate. ${ }^{42}$

Marfan syndrome is fibrous connective tissue's heritable disorder. Increased height, disproportionately, long limbs and digits, mild to moderate joint laxity, increased overjet, retrognathia, micrognathia, narrow and highly arched palate with dental crowding and dentinogenesis imperfectalike tooth conditions are frequent skeletal and dental features of this syndrome. ${ }^{41}$ De Coster et $\mathrm{al}^{43}$ concluded that there is a strong correlation between maxillary/mandibular retrognatia, long face, highly arched palate and Marfan syndrome. Moreover specific morphogenetic aspects of craniofacial complex can be explained by a combination of both intrinsic genetic and environmental factors. Westling et al ${ }^{44}$ reported that about $70 \%$ of the patients with Marfan syndrome had been referred for orthodontic treatment because of crowding and large overjet. In $36 \%$ of them, the orthodontic treatment was carried out before diagnosis or suspicion about the Marfan syndrome. Mutations in the Fibrillin (FBN) 1 gene are the major cause of Marfan syndrome. ${ }^{45}$

Human craniofacial malformations such as Crouzon, Apert and Pfeiffer syndromes have craniosynostosis, maxillary hypoplasia, relative mandibular prognathism and related dental problems and malocclusions in common and these syndromes are caused by discrete point mutations in the fibroblast growth factor receptor-2 (FGFR-2) genes which are known to affect suture development. ${ }^{46-49}$ In addition to FGFR-2, the mutation in fibroblast growth factor receptor -1 is found to be responsible for Pfeiffer syndrome. ${ }^{50}$ All of these malformations exhibit autosomal dominant inheritance..$^{41}$

Hemifacial microsomia is known as one of the most common syndromes resulting in facial asymmetry, hypoplasia of facial musculature and mandibular deficiency. Hemifacial microsomia is a common birth defect involving first and second branchial arch derivative. Its phenotype is highly variable. Although most cases are sporadic there are also familial cases exhibiting autosomal dominant, autosomal recessive or $\mathrm{X}$-linked inheritance. ${ }^{51}$

Apart from these syndromes, one of the most challenging problems to an orthodontist is perhaps caused by cleft lip and/or palate (CL/P). CL/P is a congenital malformation inherited as a discontinued multifactorial trait. ${ }^{52}$ When the balance between the genetic and the environmental influences exceed a certain threshold the malformation occurs. The further the threshold is exceeded, the more severe the malformation. In the mildest form, the lip alone is unilaterally cleft, whereas the lip is bilaterally cleft and the palatal cleft is complete in the most severe form.

Although, many environmental and developmental factors are known to play role in CL/P etiology, the genetic factors have also been defined as the causes of clefting conditions. ${ }^{2}$ The cleft studies carried on twins showed that the monozygotic and dizygotic twin concordance rates were 35 per cent and 5 per cent, respectively and these results reflect the heritability of the condition. ${ }^{53}$

Approximately, $80 \%$ of the cleft lip and palate cases are isolated cases whereas $10-15 \%$ of them are familial and $15 \%$ are syndromal. ${ }^{41}$ Since the genetics of $\mathrm{CL} / \mathrm{P}$ is very complicated, many candidate loci have been examined to identify the major gene. Transforming-growth-factor-alpha (TGFA) was found to contribute to the development of $\mathrm{CL} / \mathrm{P}$ in humans. ${ }^{54}$ However, in another study, an association between TGFA gene and CL/P could not be demonstrated, instead MSX1 and TGFB3 genes were suggested to be responsible for the pathogenesis of clefting. ${ }^{55}$ Nonsyndromic CL/P generally shows an autosomal dominant inheritance, whereas $\mathrm{X}$-linked recessive forms have also been reported. ${ }^{56}$ 


\section{CONCLUSION}

As reviewed by this article, the development of skeletal structures is partly under environmental control and partly under genetic control. Therefore, the importance of genetic basis of malocclusions cannot be denied. Up to date, there has been an immense progress in the field of genetically supported orthodontics. In the beginning of the $21^{\text {st }}$ century as the human genome project is completed, the possibility to discriminate the causes of a malocclusion will no longer be a dream as the identification of the underlying factors starts with the localization of its defective gene in the human genome. Although, it is very challenging to reveal the genetic component of most malocclusions and dental anomalies because of the polygenic nature of craniofacial traits, data provided by the human genome project have made it feasible to map inherited conditions related to the dentofacial development. However, further genetic studies are required to clearly determine all the specific genes leading to a particular skeletal variability. The rapid development in this field could lead to the genetic correction of the genetically controlled dentofacial anomalies and malocclusions, perhaps in near future.

\section{REFERENCES}

1- Mavropoulos A, Kiliaridis S. Orthodontic literature: An overview of the last 2 decades. Am J Orthod Dentofacial Orthop 2003;124:30-40.

2- Graber TM, Vanarsdall RL. Orthodontics: Current principles and techniques. St. Louis: Mosby-Year Book; 1994,19.

3- Baker CR. Similarity of malocclusion in families. Int J Orthod 1924;10:459-462.

4- Korkhaus G. Anthropologic and odontologic studies of twins. Int J Orthodont 1930;16:640-647.

5- Markovic MD. At the cross-roads of orofacial genetics. Eur J Orthod 1992;14:469-481.

6- Galton F. The history of twins as a criterion of the relative powers of nature and nurture. J Anthrop Inst 1875;5:391406.

7- Vlietinck RF. Determination of the zygosity of twins. [Master thesis]. Leuven, Belgium: Catholic University of Leuven, 1986.

8- Horowitz SL, Osborne RH, DeGeorge FV. A cephalometric study of craniofacial variation in adult twins. Angle Orthod $1960 ; 30: 1-5$.
9- Corruccini RS. Genetic analysis of occlusal variation in twins. Am J Orthod Dentofacial Orthop 1980;78:140-154.

10- Sognnaes RF, Rawson RD, Gratt BM, Nguyen NBT. Computer comparison of bitemark patterns in identical twins. $J$ Am Dent Assoc 1982;105:449-451.

11- Lundström A. Nature vs nurture in dentofacial variation. Eur J Orthod 1984;6:77-91.

12- Corruccini RS, Sharma K, Potter RHY. Comparative genetic variance and heritability of dental occlusal variables in U.S. and northwest Indian twins. Am J Phys Anthropol 1986;70:293-299.

13- Corruccini RS, Townsend GC, Richards LC, Brown T. Genetic and environmental determinants of dental occlusal variation in twins of different nationalities. Human Biol 1990;62:353-367.

14- Ngan DC, Kharbanda Dp, Byloff FK, Darendeliler MA. The genetic contribution to orthodontic root resorbtion: a retrospective twin study. Aust Orthod J 2004;20:1-9

15- Carels C. Genetics and the dento-facial complex. Orthod F. 2006;77:79-84.

16- Manfredi C, Martina R, Grossi G B, Giuliani M. Heritability of 39 orthodontic cephalometric parameters on MZ, DZ twins and MN-paired singletons. Am J Orthod Dentofacial Orthop. 1997;111:44-51.

17- Harris EF, Johnson MG. Heritability of craniometric and occlusal variables: A longitudinal sib analysis. Am J Orthod Dentofacial Orthop 1991;99:258-268.

18- Cassidy K, Harris EF, Tolley EA, Keim RG. Genetic influence on dental arch form in orthodontic patients. Angle Orthod 1998;68:445-454.

19- Susanne C. Genetic and environmental influences on morphological characteristics. Ann Hum Biol 1975;2:279-288.

20- Harris JE, Kowalski CJ. All in the family: use of familial information in orthodontic diagnosis. Am $J$ Orthod 1976;69:493-510.

21- Saunders SR, Popovich F, Thompson GW. A family study of craniofacial dimensions in the Burlington Growth Centre sample. Am J Orthod 1980;78:394-403.

22- Jena AK, Duggal R, Mathur VP, Parkhash H. Class-III malocclusion: Genetics or environment? A twins study. J Indian Soc Pedod Prev Dent 2005;23:27-30.

23- Devor EJ. Transmission of human craniofacial dimensions. J Craniofac Genet Dev Biol 1987;7:95-106.

24- Curtner RM. Predetermination of the adult face. Am J Orthod 1953;39:201-217.

25- Hunter WS. A study of the inheritance of craniofacial characteristics as seen in lateral cephalograms of 72 like sexed twins. European Orthodontic Society Report of Congress 1970;41:59-70. 
26- Savoye I, Loos R, Carels C, Derom C, Vlietinck R. A genetic study of anteroposterior and vertical facial proportions using model-fitting. Angle Orthod 1998;68:467-470.

27- Proffit WR. Contemporary Orthodontics. St.Louis; Mosby: $2000,142$.

28- Proffit WR. On the aetiology of malocclusion. Br J Orthod 1986;13:1-11.

29- Rubbrecht 0. A study of the heredity of the anomalies of the jaws. Am J Orthod Oral Surg 1939;25:751-779.

30- Wolff G, Wienker TF, Sander H. On the genetics of mandibular prognathism: analysis of large European noble families. J Med Genet 1993;30:112-116.

31- Downs WG. Studies in the causes of dental anomalies. $J$ Dent Res 1928;8:267-379.

32- Stiles KA, Luke JE. The inheritance of malocclusion due to mandibular prognathism. J Hered 1953;44:241-245.

33- Litton SF, Ackerman LV, Isaacson RJ, Shapiro B. A genetic study of Class III malocclusion. Am J Orthod 1970;58:565577.

34- Suzuki S. Studies so-called reverse occlusion. J Nihon Univ Sch Dent 1962;4:51-58.

35- Schulze C, Weise W. Zur Vererburg der Progenie. Fortschr fte Kieferorthop 1965;26:213-229.

36- Harris JE. Genetic factors in the growth of the head: Inheritance of the craniofacial complex and malocclusion. Dent Clin North Am 1975;19:151-160.

37- Peck S, Peck L, Kataja M. Class II division 2 malocclusion: a heritable pattern. Angle Orthod 1998;68:9-17.

38- Klein, D. Genetic factors and classification of craniofacial anomalies derived from a perturbation of the first branchial arch. In Longacre, J.J. (editor): Craniofacial anomalies ; pathogenesis and repair. Philadelphia, J.B; Lippincott company: 1968;31-41.

39- Warkany J, Kalter H. Congenital malformations. New Engl J Med 1961;265:993-1001.

40- Cohen M. In Bell WH, Proffit WR, White RP. Surgical correction of dentofacial deformities. Philadelphia; WB Saunders:1980;23.

41- http://ncbi.nlm.nih.gov/OMIM

42- Dixon, MJ. Treacher Collins syndrome. Hum Molec Genet 1996;5:1391-1396.

43- De Coster PJ, De Paw G, Martens L, De Paepe A. Craniofacial structure in Marfan syndrome: a cephalometric study. Am J Med Genet 2004;pp240-248

44- Westling L, Mohlin B, Bresin A. Craniofacial manifestations in the Marfan syndrome: palatal dimensions and a comparative cephalometric analysis. J Craniofac Genet Dev Biol 1998;18: 211-218.
45- Robinson PN, Godfrey M. The molecular genetics of Marfan syndrome and related microfibrillopathies. J Med Genet 2000;37:9-25

46- Goriely A, Mc Vean GA, Röjmyr M, Ingemarsson B, Wilkie AOM. Evidence selective advantage of pathogenic FGFR2 mutations in the male germ line. Science 2003;301:606-607

47- Rutland P, Pulleyn LJ, Reardon W, Baraitser M, Hayward R, Jones B, Malcolm S, Winter RM, Oldridge M, Slaney SF, Poole MD, Wilkie AOM. Identical mutations in the FGFR2 gene cause both Pfeiffer and Crouzon syndrome phenotypes. Nature Genet 1995;9:173-176.

48- Lajeunie E, Ma HW, Bonaventure J, Munnich A, Le Merrer M, Renier D. FGFR2 mutations in Pfeiffer syndrome. (Letter). Nature Genet 1995;9:108.

49- Wilkie AO. Craniosynostosis: genes and mechanisms. Hum Mol Genet 1997;6:1647-1656.

50- Robin NH, Feldman GJ, Mitchell HF, Lorenz P, Wilroy RS, Zackai EH, Allanson JE, Reich EW, Pfeiffer RA, Clarke LA, Warman ML, Mulliken JB, Brueton LA, Winter RM, Price RA, Gasser DL, Muenke M. Linkage of Pfeiffer syndrome to chromosome 8 centromere and evidence for genetic heterogeneity. Hum Molec Genet 1994;3:2153-2158.

51 - Taysi K, Marsh JL, Wise DM. Familial hemifacial microsomia. Cleft Palate J 1983;20:47-53.

52- Murray JC. Face facts: genes, environment, and clefts. Am J Hum Genet 1995;57:227-232.

53- Connor, Ferguson S. Essential medical genetics. Oxford; Blackwell, 4th edn: 1993,127.

54- Ardinger HH, Buetow KH, Bell GI, Bardach J, VanDemark DR, Murray JC. Association of genetic variation of the transforming growth factor-alpha gene with cleft lip and palate. Am J Hum Genet 1989;45:348-353.

55- Lidral A, Romitti PA, Bassart AM, Doetschman T, Leysens NJ. Association of MSX1 and TGFB3 with nonsyndromic clefting in humans. Am J Hum Genet 1998;63:557-568.

56- Rollnick BR, Kaye $\mathrm{Cl}$. Mendelian inheritance of isolated nonsyndromic cleft palate. Am J Med Genet 1986;24:465473 